UCRL - JC- -105825

PREPRINT

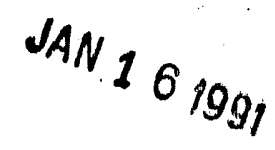

New Biomedical fxpplications of Radiocarbon

\author{
J. C. Davis
}

This paper was prepared for submittal to the 40th Anniversary Coriference on Radiocarbon, Lake Arrowhead, CA, June 1990

December 1990

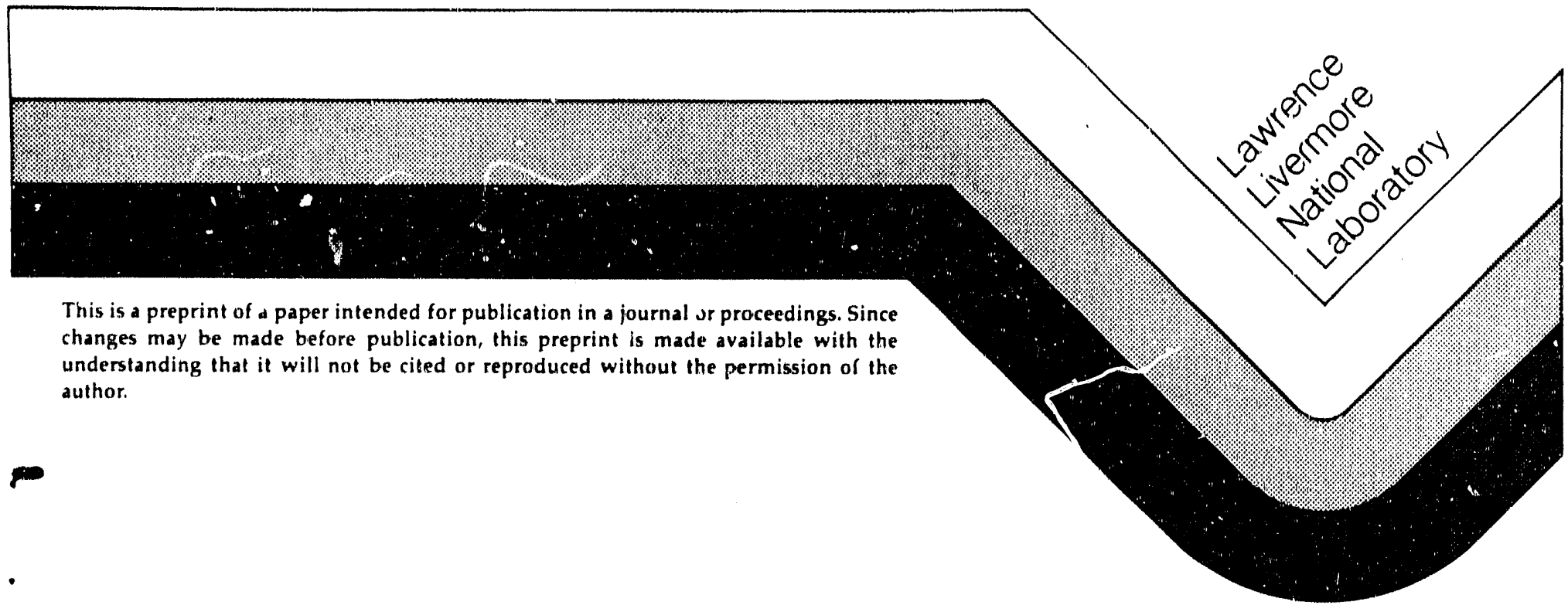




\section{DISCI.AIMIER}

This document was prepared as un account of work sponsored by an agency of the l nited States Government. Neither the linited States Government nor the University of California nor any of their employees, makes any warranty, express or implied, or assumes an! lekal liability or responsibility for the accuracy, conipleteness, or useful. netss of any information. apparatus, product, or process disclosed, or represents that its use would not infringe privately on ned rights. Reference herein to any specific commercial products, process, or service by trade name, trademark. manufacturer, or otherwise. does not necessarily constitute or imply ifs endorsement, recommendation. or favoring by the Inited Siates Government or the liniversity of California. The views and opinions of authors expressed herein do not necessurily state or reflect those of the United States Government or the University of California, and shall not be used for advertising or product endorsement purposes. 


\title{
New Biomedical Applications of Radiocarbon
}

\author{
J. C. Davis \\ Center for Accelerator Mass Spectrometry \\ Lawrence Livermore National Laboratory \\ University of California \\ Livermore, California 94550 \\ UCRL-JC- -105825 \\ DE9 I 006249
}

\section{Introduction}

The development of accelerator mass spectrometry (AMS) and its rapid application to radiocarbon detection produced a revolution in archaeology, earth science, and oceanography for two primary reasons: The sample size required to achieve a reliable date was reduced by $>1000$, permitting multiple dates and greater precision. Further, the detection ("machine") background was reduced to less than the contaminations caused by sample preparation, thus greatly increasing the sensitivity for routine analysis. These increases in sensitivity and precision have had qualitative, as well as quantitative effects on these disciplines. For similar reasons, considerable impact upon biomedical science was predicted, but not tested until recently. Radiocarbon is the premier tracer for following many biological reaction pathways. Radiocarbon is non-labile in many organic molecules and may be placed in specific sites with known binding properties. Unlike many other substitutional tracers, ${ }^{14} \mathrm{C}$ does not distort the structure of the host molecule. At the concentrations one can easily predict for AMS analyses, the danger of radiolytic perturbation of the biochemistry under study is essentially zero. Similarly, the radiation dose to the host organism from decay of ${ }^{14} \mathrm{C}$ is negligible in design of an experiment.

The potential of AMS and radiocarbon in biomedical work was suggested specifically at the first AMS conference.1) Subsequently, a speculative description of possible biomedical uses of ${ }^{14} \mathrm{C}$ and other isotopes was provided by Elmore. ${ }^{2)}$ Despite the potential value of this use of radiocarbon detection, no application combining AMS analysis and radiocarbon in biomedicine was reported until this year. ${ }^{3)}$ The slowness to exploit this possibility has two explanations, one sociological and one technical. The time required for a technique to achieve maturity in one field and then jump disciplinary boundaries is frequently more than a decade. Given that AMS truly became a routine tool in archaeology and the earth sciences only in the mid-1980s, such a lag is perfectly normal. Additionally, there is a genuine technical obstacle. All the laboratories performing both AMS and conventional radiocarbon analyses for archaeology, oceanography and the earth sciences deperici upon their ability to measure radiocarbon at or below natural abundance. The consequences for such ongoing programs of a single mistake with compounds or samples

This work was performed under the auspices of the U. S. Department of Energy at the Lawrence Livermore National Laboratory under contract W-7405-Eng-48.

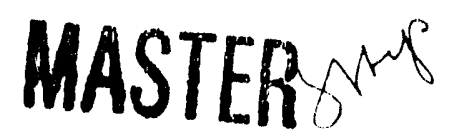


of materials intentionally labeled a $1000 \mathrm{X}$ to $10^{6} \mathrm{X}$ the natural abundance are trivially easy to predict.

The motivation to overcome these obstacles exists within the biomedical research effort at LLNL. A specific assignment of the biomedical and environmental activities of the Department of Energy is the assessment of the risk and consequences of the generation and use of energy. A major component of such assessment is dosimetry for exposure to radiation and to carcinogenic and/or mutagenic materials. The dilemma of such assessment is illustrated in Figure 1. One wishes to know the response of an organism to some chemical insult at the environmentally relevant risk level. However, due to limitations of technique, methodology, etc., one often must measure the dose-response curve at higher dose; then extrapolate to the much lower environmental dose. The extrapolation is uncertain as to whether the response is linear, whether damage repair mechanisms actually result in no response (and hence no risk) occurring at low dose, or whether there is some finite threshold risk at any dose. As legal rule-making and significant economic consequences follow from the assigned risk, however derived, the motivation to provide better diagnostic techniques at low exposures is powerful. We have begun a program at LLNL to exploit the sensitivity of AMS for radiocarbon to provide such information.

\section{Experimental Capabilities}

The spectrometer 4,5$)$ used for measurement in the initial research applications of AMS to biomedical problems is the UC/LLNL AMS beamline at the LLNI Multiuser Tandem Laboratory. This spectrometer was co-funded by LLNL for geochemistry research and by the UC Regents for archaeological and anthropological research. The decision to attempt biomedical experiments was made in a proposal for internal discretionary research funds at LLNL intended for use in creating new program opportunities across disciplinary lines. The research proposal was a collaborative effort of nuclear physics, nuclear chemistry, biomedical sciences, and environmental sciences staff.

Unique aspects of this spectrometer include $5 \mathrm{~cm}$ magnet apertures, $10 \mathrm{~cm}$ optics elsewhere, and a 60 sample Cs sputtering ion source with spherical ionizer assembly.6) As samples in this ion source are stored in a cassette several $\mathrm{cm}$ behind the working point of the ion source, are individually exposed to the $\mathrm{Cs}$, and then replaced in the cassette, it was felt that this design would have adequate protection against cross contamination of samples having widely different ${ }^{14} \mathrm{C}$ concentrations. An accidental contamination of the sample graphitizer and ion source of the Simon Fraser AMS group 7$)$ during preparatory tests for these experiments proved to be recoverable, so we were confident that both biomedical and archaeological programs could co-exist on the same spectrometer.

Sample preparation for experiments to date utilizes the graphitization technique of Vogel. ${ }^{8)}$ The graphitization facility for biomedical samples is $\sim 0.5 \mathrm{~km}$ downwind from the spectrometer and the preparation lab used for natural samples. The preparation protocol for all samples is to perform dilutions of extracied organic 
material before graphitization so that neither the graphitizer nor the spectrometer ever sees material greater than 100 Modern. Sample handling and graphitization is performed from lowest to highest isotope concentration with calibration standards (typically ANU sugar) and backgrounds prepared between unknowns as a check against contamination. As described below, these protocols are adequate to monitor contamination, but instances of sample contamination have occurred, confirming the initial fears of other laboratories. These problems have arisen because the extreme sensitivity of AMS requires careful protocols in laboratories accustomed to using large amounts of ${ }^{14} \mathrm{C}$. However, irrecoverable disasters have not occurred, and new protocols and experience should make AMS more readily available to biomedicine.

\section{Initial Experiments}

Our initial experiment was a measurement of the dose-response curve for DNA damage caused in mouse liver cells by a specific carcinogen: 2-amino-3,8dimethylimidazo[4,5-f]quinoxaline, or MeIQx. This compound is present in the human diet, from meat fried at high temperzture. As most cancer is mediated or initiated by genetic fault, the covalent binding of a MeIQx metabolite to DNA, (DNA adduct), is taken to be indicative of genetic cell damage. We have measured ${ }^{3)}$ the formation of adducts in mouse liver DNA twenty-four hours after administering a dose of $\mathrm{MeIQx}$ labeled at a single location with ${ }^{14} \mathrm{C}$. The liver DNA was isolated, extracted and dialyzed to remove residual non-covalently bound metabolites, then diluted 10- to 1000-fold with sodium lauryl sulfate (SDS) solution previously deterrnined to be 0.4 Modern, graphitized, and the ${ }^{14} \mathrm{C}$ content determined by AMS. The dose-response curve expressed in terms of adducts per $10^{12}$ nucleotides on DNA is shown in Figure 2 for a dose range from $500 \mathrm{pg} / \mathrm{kg}$ to $5 \mathrm{mg} / \mathrm{kg}$ of body weight. Three separate animals were measured at each dose. The low doses approximately the chemical doses as low as those expected from the human consumption of several hamburgers.

As can be seen in Figure 2, the dose-response curve is linear from a dose of $500 \mathrm{ng} / \mathrm{kg}$ to $5 \mathrm{mg} / \mathrm{kg}$ of body weight. These results extrapolate linearly to other adduct concentrations reported previously from our laboratory and others $\left.{ }^{9}, 10\right)$ for animals given much higher doses of MeIQx. The measurements at higher dose use a $32 \mathrm{P}$-postlabeling technique that presents both radiological hazards for the experimenters and requires quantification through procedures which may have uncertain efficiencies. The present measurements are able to detect one ${ }^{14} \mathrm{C}$-labeled adduct per $10^{11}$ nucleotides, an improvement in sensitivity of one order of magnitude over the best adduct measurements to date. Additionally, these measurements are three to five orders of magnitude better than traditional quantitative adduct measurement. Reproducibility in these measurements is high $(\sim 10 \%)$ and may be limited by animal to animal variation. Instrument precision for this work was $2 \%$, which should allow studies of the animal to animal variations of these responses.

There are two obvious limitations at the low-dose end of the experiment. First, we cannot expect to detect adducts at levels below one per $10^{12}$ nucleotide pairs 
because of the ${ }^{14} \mathrm{C}$ naturally present in tissue. The dose-response curve should go flat at that level because of the natural isotopic abundance of ${ }^{14} \mathrm{C}$, not because of biology. In fact, we did not reach the natural abundance limit because of contamination of samples with ${ }^{14} \mathrm{C}$ from conventional scintillation counting experiments previously performed in the biomedical research areas. For example, a swipe from a hood in one sample extraction area used in the initial work was measured as 18,000 Modern.

Also shown in Figure 2 is the easily achieved background level for biomedical AMS, $0.5-1 \%$ Modern. If biological hosts could be grown depleted in ${ }^{14} \mathrm{C}$, another two orders of magnitude in the sensitivity of detection of adducts will be made possible. For many materials, this sensitivity would allow determination of DNA damage at doses below those of environmental exposure, clearly defining one component of risk assessment without extrapolation.

As a check on the initial experiment and the more stringent protocols developed for sample handling and preparation, another set of mice were dosed with the toxic and potent carcinogen 2,3,7,8-tetrachlorodibenzo-p-dioxin, TCDD or dioxin. TCDD is rapidly absorbed, but the molecule does not readily react directly with DNA and should not form adducts. The TCDD used in this study was fully substituted with ${ }^{14} \mathrm{C}$, giving us 12 times greater sensitivity than in the MeIQx adduct study. In Figure 3, the ${ }^{14} \mathrm{C}$ content of liver DNA from animals dosed with TCDD is plotted in units of Modern. For comparison, the results of the MeIQx experiment are shown as well. No evidence of formation of adducts is seen, except possibly at the highest dose, corresponding to the $\mathrm{LD}_{50}$ for this species. At that toxicity, off-normal metabolic effects might explain some binding to DNA. Secondly, improved protocols have minimized contamination of the DNA samples and we are unaffected by the presence of unbound TCDD throughout the bulk tissue, except possibly at the highest dose: at the $L D_{50}$ dose, the DNA isolate was 20 Modern while the whole livers themselves were approximately $10^{6}$ Modern.

\section{Work in Progress}

Demonstration of the sensitivity and utility of AMS for detecting radiocarbon tags in biomedical applications has led to numerous follow-on expcriments. Several topics being pursued at present include the following:

Carbon-14 Depleted Hosts - As pointed out above, hosts depleted in ${ }^{14} \mathrm{C}$ offer two orders of magnitude gain in sensitivity for these measurements. We have succeeded in growing methanotropic bacteria on methane generated from petroleum. The ${ }^{14} \mathrm{C}$ content of the bacteria has been measured at $1 \%$ Modern. We are currently growing mice on a special diet. The first generation of animals grown on this diet average $70 \%$ Modern in bulk tissue. Although we are pursuing development of such animals for toxicology studies, their utility for nutritional work cannot be overemphasized. If mice depleted to $1 \%$ in ${ }^{14} \mathrm{C}$ can be successfully grown, then any natural foodstock is inherently tagged, allowing detailed tracing of metabolic pathways. Experiments with these hosts could be safely performed by any AMS laboratory, greatly expanding the measurement base. 
Dose and Time Dependence Studies - Our ability to measure extremely small amounts of extracted DNA (samples of $\sim 1 \mu \mathrm{g}$ before dilution) makes possible following the rates of damage and repair in organisms as a function of dose. Not just the shape of the dose-response curve but its time history are important in the assessment of risk. We have begun experiments with collaborators at the National Institutes of Health/National Cancer Institute to measure the adduct kinetics of carcinogen adducts in lymphocytes of primates, making maximal use of precious primate research subjects by extracting only small blood samples instead of taking larger biopsies.

Measurement of Chemotherapy Dose - Accurate adjustment of the treatment level in chemotherapy is important but is difficult, as one wishes to work near the cytotoxic limit in patients with weak and varying metabolisms. We have begun a collaboration to study the metabolism of anticancer drugs in normal and resistant tumors using mouse models and human cancer patients. It may be possible to design therapy regimes that can be monitored in real time to adjust dose optimally for individual patients. In such applications, the chemical toxicity of the drugs being used would be more significant than the small radiation dose incurred. For example, a normal $500 \mathrm{ng} / \mathrm{kg}$ dose level would produce a radiation dose to a human subject of 0.003 milliSieverts based on a 24-hour half-life for the compound, approximately $1 \%$ of the normal annual exposure.

Optimal Sample Preparation and Spectrometers - The graphitization technique most widely used for AMS studies ${ }^{8}$ ) was designed to produce the highest possible accuracy and repeatability for the measurement of natural samples. In the present area, biological noise and host-to-host variation may well limit absolute accuracy to $5 \%$ or more. At the same time, experiments can easily be envisioned in which 100's of samples need to be measured. Development is in progress on one- or two-step batch techniques in which numerous organic samples are formed into solids compatible with satisfactory performance in our sputtering ion source. Initial tests have produced materials with current yields $25-50 \%$ of those prepared in the standard way and yielding measurement accuracy of $1-2 \%$. Reduction of this technique to routine practice will greatly increase measurement throughput.

Similarly, spectrometers designed for archaeological work are overcomplex and too expensive for clinical fielding. As one may regard the initial ${ }^{14} \mathrm{C}$ level as somewhat of a free parameter, simpler devices may be adequate for research in this field. A notional design for a simple machine capable of both tritium and radiocarbon measurements is shown in Figure 4. By placing the ion source directly on the tandem accelerator, one achieves simultaneous injection of all isotopes in the simplest possible manner. Initial tests ${ }^{11)}$ of this configuration using our own spectrometer suggest that successful operation at the required accuracy is possible. If the scientific results of our work create the measurement demarid expected, we will seek funding to build a prototype of such a device. 


\section{Summary}

The initial experiments applying AMS to the use of radiocarbon in biomedical research have demonstrated the expected sensitivity and utility. The ability to perform research with labeled compounds without interfering with work done on natural abundance materials has also been demonstrated. Sufficient follow-on activities have been identified in a wide variety of applications to ensure growth of this new subfield. While other isotopes, particularly tritium, may have considerable utility in specific research tasks, the chemical properties of carbon and the fully developed technology for measuring its isotopes assure that radiocarbon will remain at the center of all future work.

\section{Acknowledgements}

Development of the biomedical research program to utilize AMS has involved open and enthusiastic collaboration and cooperation across disciplinary and organizational lines. John Vogel and Ken Turteltaub performed the initial experiments and developed the sample handling protocols, Ivan Proctor and John Southon brought the spectrometer into operation, Marc Caffee and Bob Finkel built the detector and data acquisition system, and Mark Roberts has developed specialized control algorithms for spectrometer operation. Erle Nelson, Bart Gledhill and Jim Felton have provided ideas, encouragement, support and critical review since the inception of this activity. Without the efforts of all of the above, little would have been possible. 


\section{References}

1) J. Keilson and C. Waterhouse, Proc. First Conf. on Radiocarbon Dating with Accelerators, H. E. Gove, ed. (Univ. of Rochester, 1978) p. 391.

2) D. Elmore, Biol. Trace Element Res. 12 (1987) 231.

3) K. W. Turteltaub, et al., "Accelerator Mass Spectrometry in Biomedical Dosimetry: Relationship Between Low-level Exposure and Covalent Binding of Heterocyclic Amine Carcinogens to DNA," Proc. Natl, Acad. Sci. USA, Vol. 87, pp. 5288-5292 (1990).

4) J. C. Davis, et al., "LLNL/UC AMS Facility and Research Program," Fifth Intl. Conf. on AMS, Paris, France, April 1990.

5) J. R. Southon, et al., "The New LLNL AMS Spectrometer," Fifth Intl. Conf. on AMS, Paris, France, April 1990.

6) I. D. Proctor, et al., "The LLNL Ion Source - Past, Present and Future," Fifth Intl. Conf. on AMS, Paris, France, April 1990.

7) J. S. Vogel, J. R. Southon and D. E. Nelson, Radiocarbon 32 (1990) 81.

8) J. S. Vogel, D. E. Nelson and J. R. Southon, Radiocarbon 29 (1987) 323.

9) K. Yamoshita, A. Umemoto, S. Grivas, S. Kato, and T. Sugimura, Mutagenesis 3 (1988) 515.

10) K. W. Turteliaub, B. E. Watkins, M. Vanderlaan, and J. S. Felton, Carcinogenesis 11 (1990) 43.

11) M. L. Roberts, J. R. Soutrion, J. C. Davis, I. D. Proctor and D. E. Nelson, Proceedings on the Eleventh International Symposium on the Application of Accelerators in Research and Industry, Denton, Texas, 1990, Nucl. Inst. and Meth., to be published.

12) J. S. Felton, et al., "Accelerator Mass Spectrometry in the Biomedi، I Sciences: Applications in Low-Exposure Biomedical and Environmental Dosimetry," Fifth Intl. Conf. on AMS, Paris, France, April 1990. 


\section{Figure Captions}

Figure 1 Hypothetical behavior of dose-response curves when extrapolated to low dose, beyond usual measurement thresholds.

Figure 2 Dose-response curve for production of DNA adducts by MeIQx. ${ }^{3)}$

Figure 3 Radiocarbon content of mouse liver DNA exposed to MeIQx and TCDD. ${ }^{12)}$

Figure $\Delta_{t} \quad$ Schematic of small accelerator optimized as a spectrometer for simultaneous AMS measurement of tritium and radiocarbon.

$12 / 4 / 90$ 


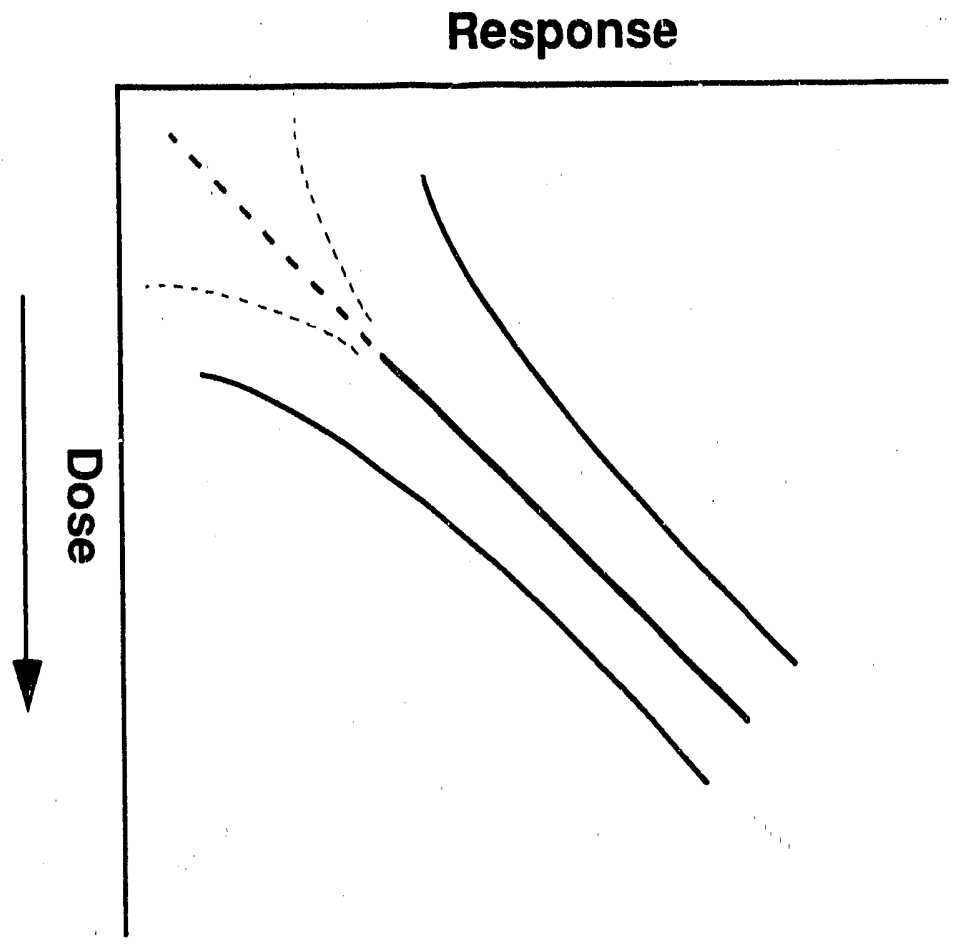

Figure 1 


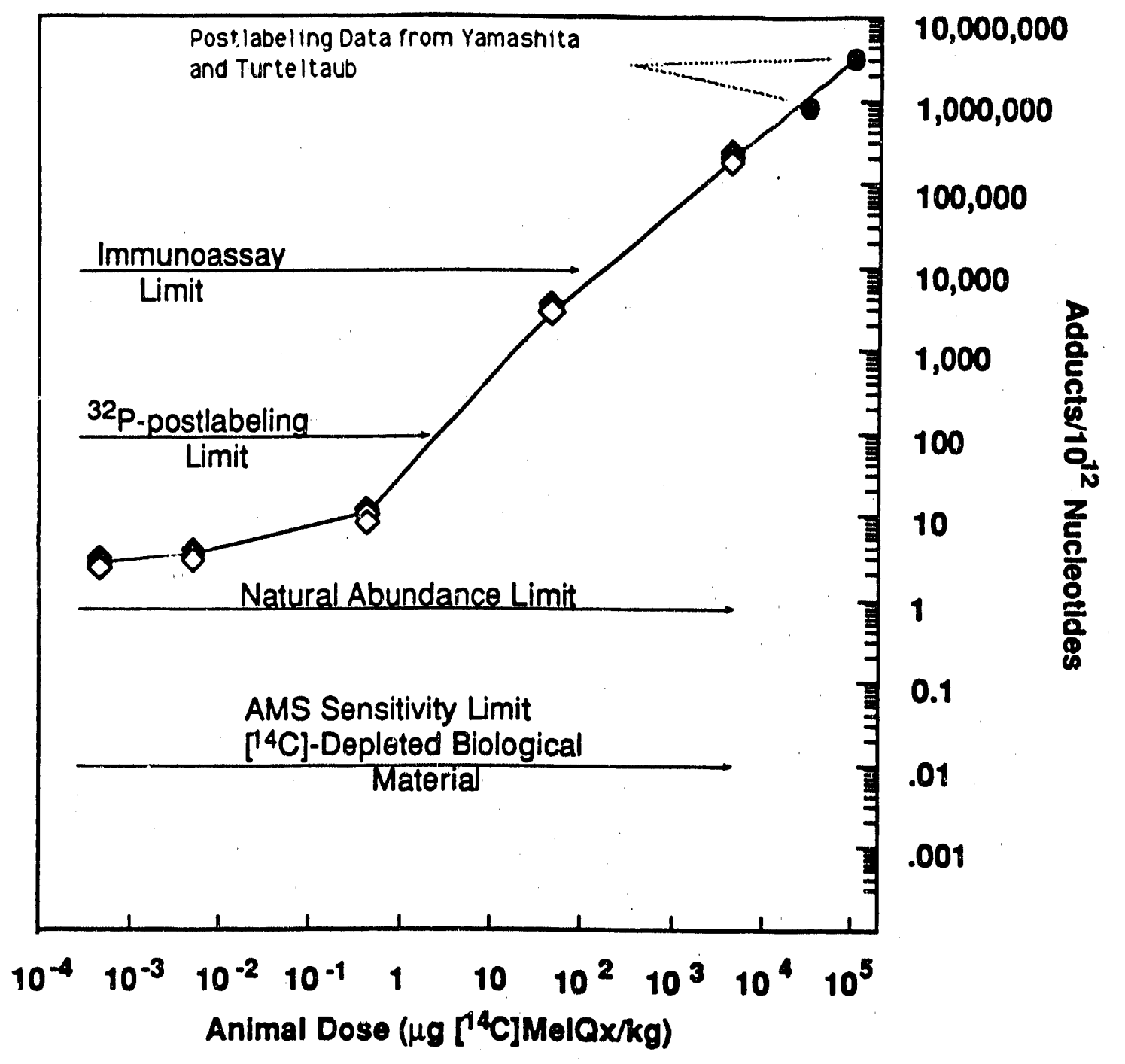

Figure 2 


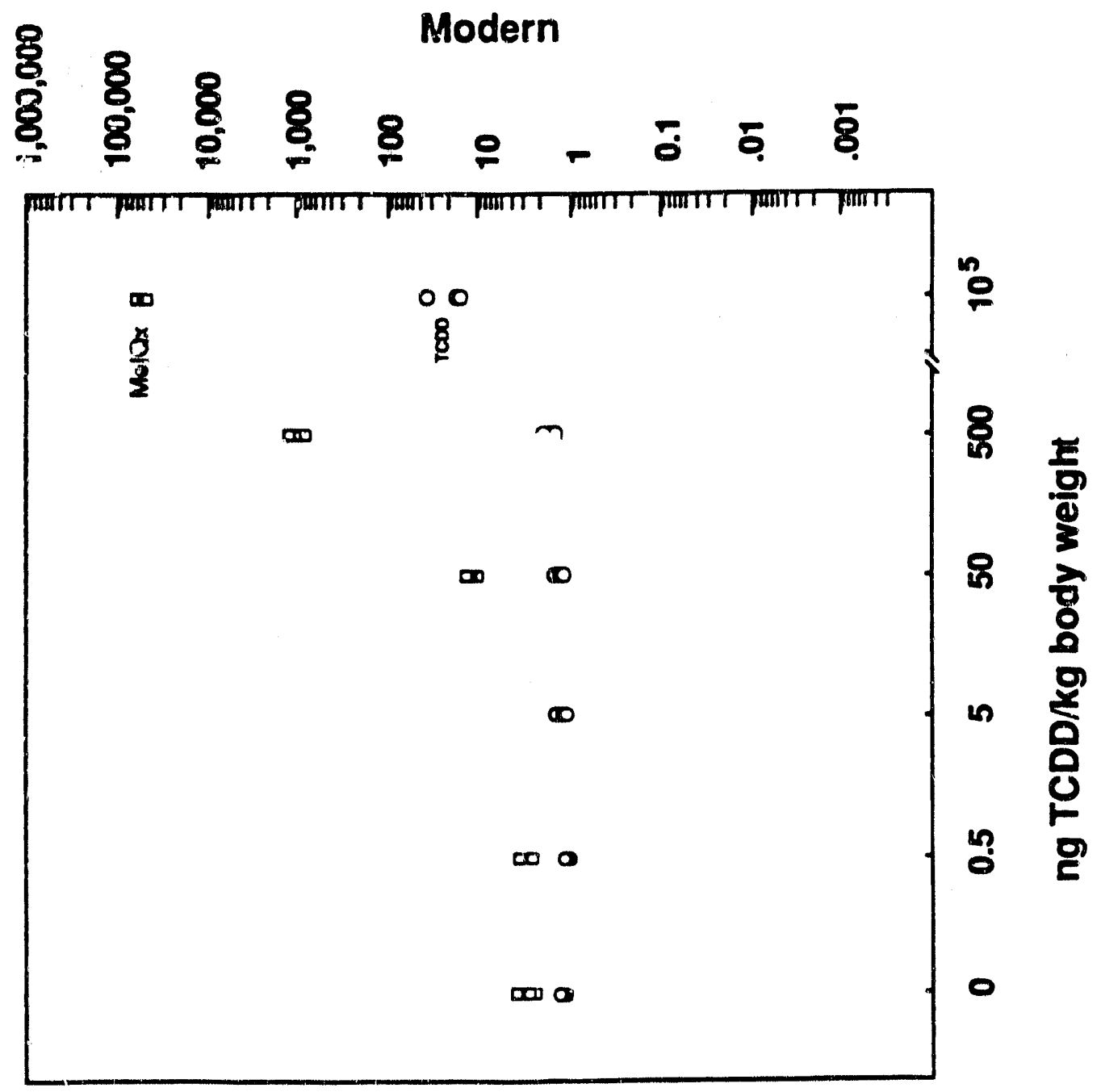

Figure 3 


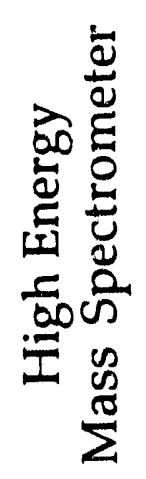

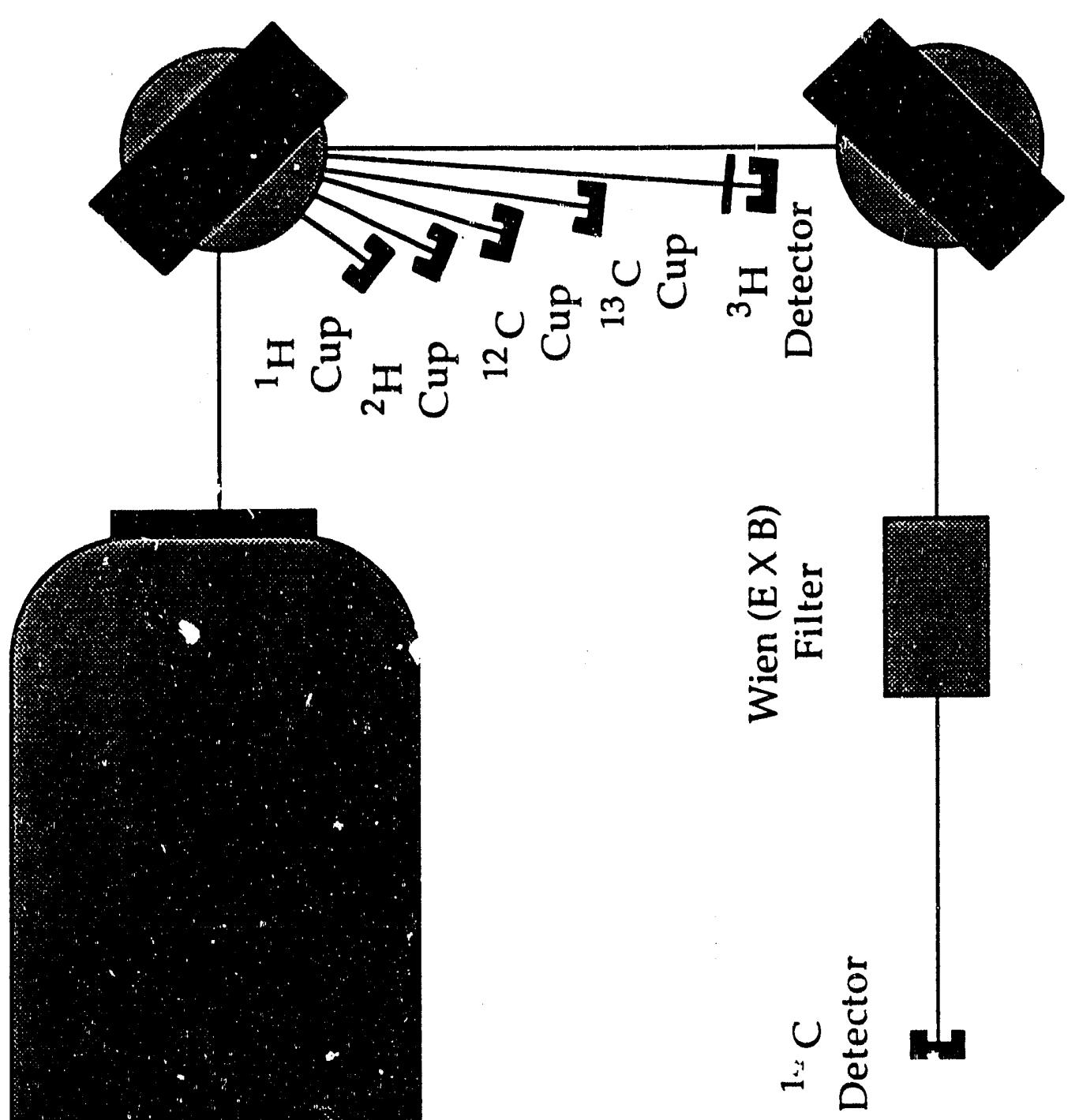

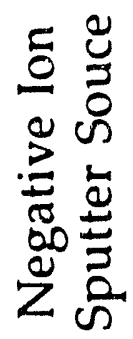

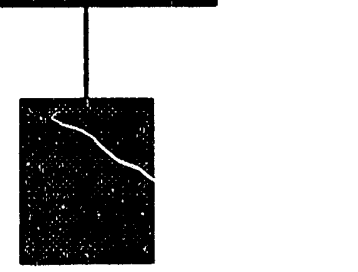

Figure 4 

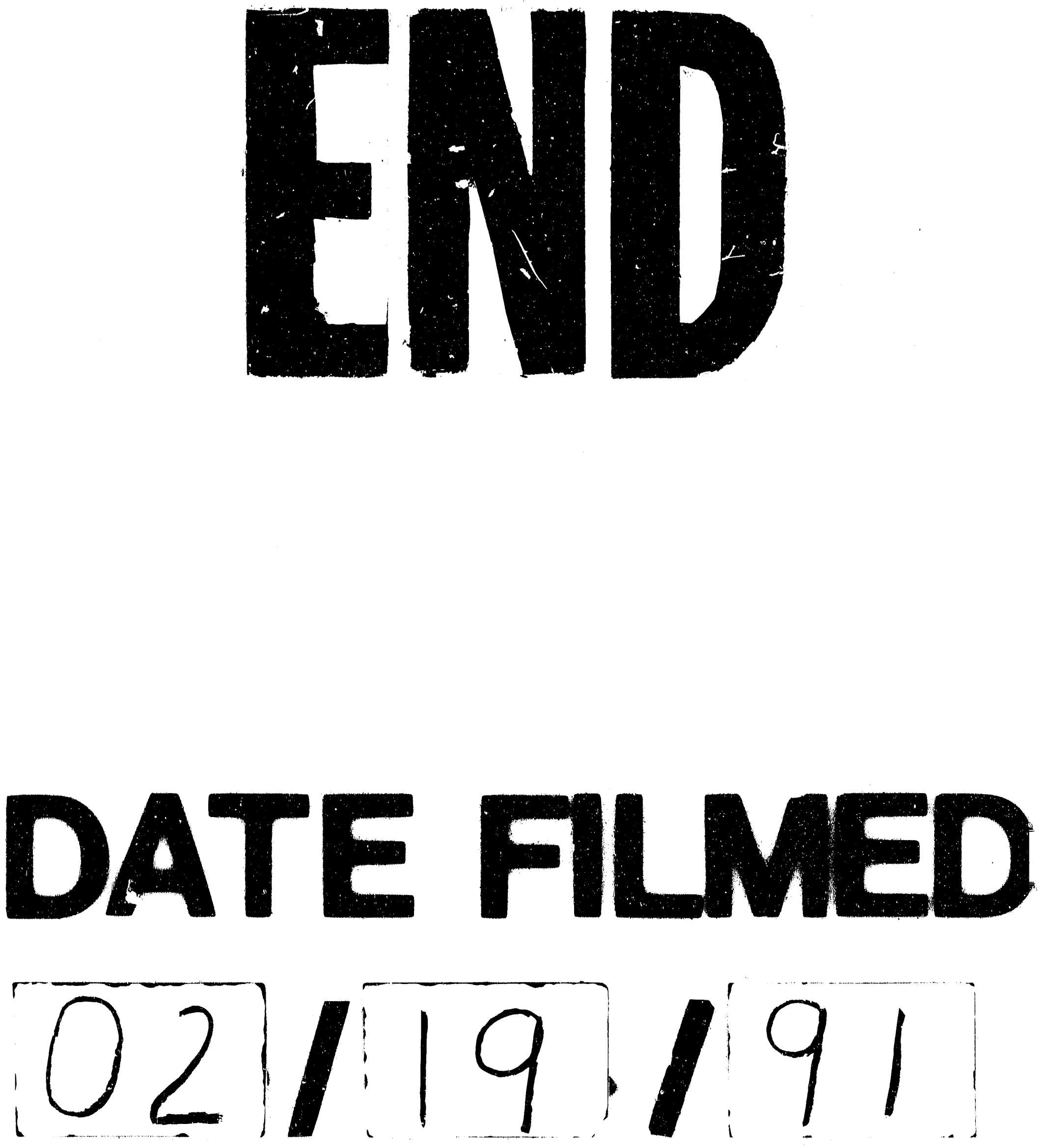
